Check for updates

Cite this: RSC Adv., 2018, 8, 30148

\title{
An approach toward miRNA detection via different thermo-responsive aggregation/disaggregation of CdTe quantum dots $\uparrow$
}

\author{
Yasaman Sadat Borghei and Morteza Hosseini (DD *
}

MicroRNA-155 regulates the expression of 147 target genes that are involved in cancer pathways, and its expression level has been shown to be up-regulated in breast cancer. Thus, it is necessary to investigate the value of microRNA-155 for early diagnosis and prognosis of breast cancer. Here we present a novel and "light shift" spectral method for the detection of miRNA based on different thermo-responsive aggregation/disaggregation of CdTe quantum dots (CdTe QDs) by using single stranded DNA or a DNA/ RNA heteroduplex as a template after heat treatment. In this method upon addition of the DNA/RNA heteroduplex, the CdTe QDs aggregate strongly due to their strong interaction with the double stranded nucleic acid, which results in fluorescence quenching. By applying the melting temperature $\left(T_{\mathrm{m}}\right)$, the DNA/RNA heteroduplex denatures and two strands are dissociated, which disaggregates the QDs, effectively switching to fluorescence emission of QDs. These processes were investigated with Atomic Force Microscopy (AFM) and fluorescence spectroscopy. The proposed method has been used also for the determination of miR-155 in total RNAs extracted from the human breast carcinoma SK-BR-3 cells and normal human embryonic kidney cell line (HEK 293).

Received 18th May 2018

Accepted 19th August 2018

DOI: $10.1039 / \mathrm{c} 8 \mathrm{ra} 04257 \mathrm{~h}$

rsc.li/rsc-advances

\section{Introduction}

MicroRNAs (miRNAs or miRs) are small single stranded noncoding RNA that regulate the expression of multiple genes. ${ }^{1}$ The difference in the expression level of miRNAs causes the onset of diseases, including several cancers, such as breast cancer (BC). ${ }^{2}$ In general, miRNAs are often classified into two categories: oncogenic miRNAs ("oncomir") (act by expression of tumor suppressor genes) and the tumor suppressor miRNAs (act by silencing oncogenes). ${ }^{3}$ MiR-155 is an oncogenic miRNA or a tumor suppressor. ${ }^{4}$ Recently, several studies showed that up-regulation of miR-155 occurred in $\mathrm{BC}$ and which make it an appropriate biomarker for BC diagnosis. ${ }^{3,5}$ Conventional techniques for detecting miRNAs are northern blotting, reversetranscription polymerase chain reaction (RT-PCR), and miRNA arrays. However, all of these methods display some limitations and do not meet the current demands. So, there is an urgent need to develop efficient and low-cost miRNA detection methods. To that end, the rapid development of nanotechnology has resulted in new tools for DNA and miRNA detection, including nanoparticle-derived probes, isothermal amplification, electrochemical methods, and DNAzyme based reporters..$^{6-15}$

Department of Life Science Engineering, Faculty of New Sciences \& Technologies, University of Tehran, Tehran, Iran. E-mail: smhosseini@khayam.ut.ac.ir

$\dagger$ Electronic supplementary information (ESI) available. See DOI: $10.1039 / \mathrm{c} 8 \mathrm{ra} 04257 \mathrm{~h}$
Recently, the unique photophysical and electronic properties of semiconductor nanoparticles or quantum dots (QDs) have attracted extensive application studies in many fields, especially in biosensing and biomedicine imaging. ${ }^{16}$ Similar to other nanoparticle colloids such as gold nanoparticle, the disturbance in the surface charge of QDs exerts a great influence on the stability of its corresponding suspension, and meanwhile, fluorescence change and a bathochromatic shift (also commonly called a red shift) of the fluorescence emission peak happens due to the particle aggregation caused by this impaired stability in surface charge. ${ }^{17}$ There are several advantages in using QDs such as narrow excitation bands, small effective Stokes shifts, broad emission bands, and susceptibility to photobleaching. ${ }^{18}$ The fluorescence transduction of QDs to the direct interactions occurring at the surface is very sensitive in such a way that these interactions have significant importance in the efficiency of the radiative recombination, either leading fluorescence activation or quenching. These changes allow us to specifically identify a particular analyte in a complex mixture. ${ }^{19}$ Previously, researchers described hydrogen-bonding interactions between oligonucleotides and quantum dots capped with mercaptoacetic acid ligands. ${ }^{20}$ Other results showed that the chalcogenide QDs interact electrostatically through their own metallic center of the with the oxygen or nitrogen site of DNA bases. On the other hand, The chalcogenide QDs interact strongly with negatively-charged phosphate groups on the DNA backbones due to their positive charge of metal ions. ${ }^{21-27}$ 


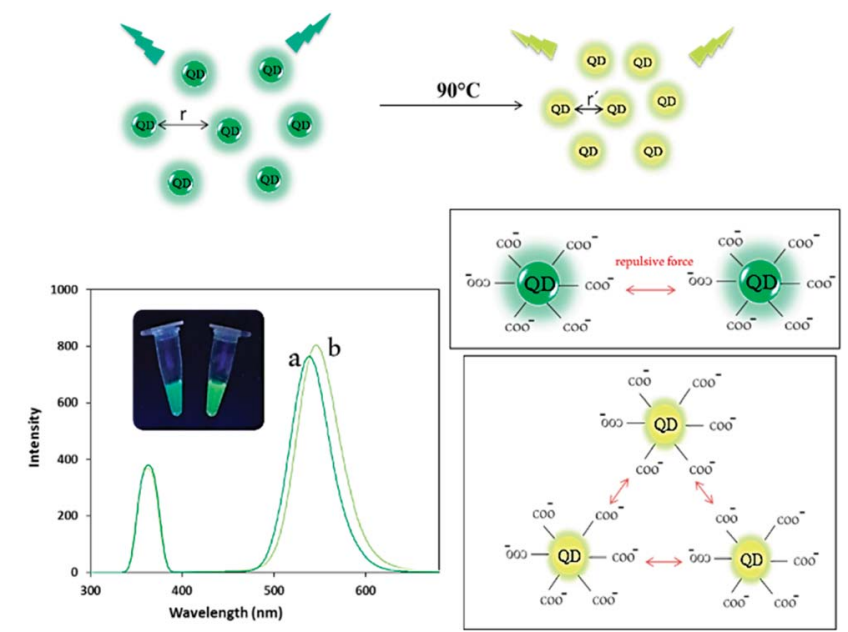

Scheme 1 Schematic representation of the fluorescent behavior of bare QDs before (a) and after (b) heating and their spectra and photographs of them before and after heat treatment.

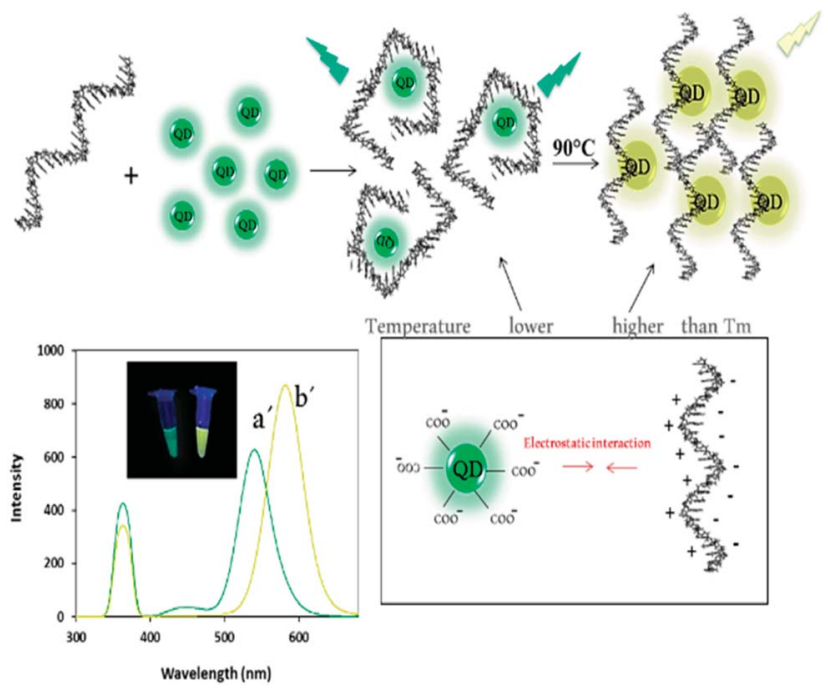

Scheme 2 Schematic representation of the fluorescent behaviour of ssDNA-QDs complex before $\left(a^{\prime}\right)$ and after $\left(b^{\prime}\right)$ heating and their spectra and photographs of them before and after heat treatment.

We used aggregation assay of CdTe QDs using heteroduplex as a new fluorescent nanosensor to achieve the objectives of the miRNA analysis. We showed that both the quenching and a bathochromatic shift mechanisms could be occurred before and after denaturation of heteroduplex, respectively, through aggregation/disaggregation between QDs and DNA/miRNA heteroduplex. Here, this nucleic acid heteroduplex aggregates thioglycolic acid (TGA)-stabilized CdTe QDs; and as a result, fluorescence quenching occurs. ${ }^{28-32}$ Applying melting temperature $\left(T_{\mathrm{m}}\right.$ : is defined as the temperature at which half of the double strand begins to dissociate), resulted in a larger Stoke's shift emission change upon the de-aggregation, ${ }^{32-36}$ which depends on the concentration of miRNA. This is due to the shorter distances between the CdTe QDs in the heteroduplex

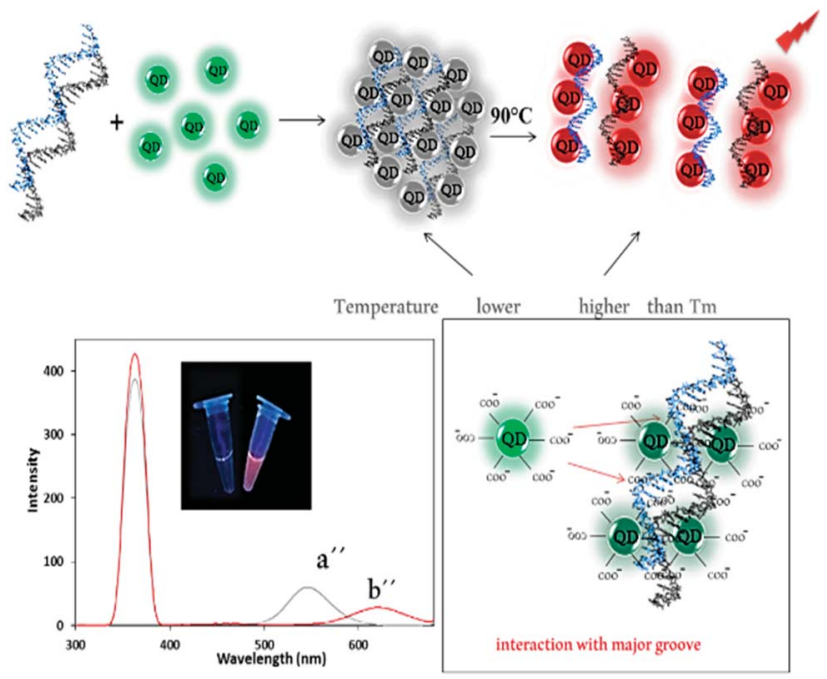

Scheme 3 Schematic representation of the fluorescent behavior of dsDNA/miR-155-QDs complex before $\left(a^{\prime \prime}\right)$ and after $\left(b^{\prime \prime}\right)$ heating and their spectra. Photographs of them before and after heat treatment.

than that of the single strand and free CdTe QDs, which can increase the dipole-dipole interaction between the CdTe QDs, resulting in a larger Stoke's shift emission change (Schemes 1$3)$. The proposed method can be used as a highly selective nanosensor for duplex/heteroduplex nucleic acid detection. The present assay was successfully applied for the determination of miRNA-155 in human breast cancer cells (SK-BR-3). The implemented miRNA can also be replaced with other miRNAs.

\section{Experimental}

\subsection{Apparatus}

All fluorescence measurements were monitored using a Perkin Elmer LS-55 fluorescence spectrometer with a xenon lamp as source of excitation while the spectral band widths of monochromators for excitation and emission were $10 \mathrm{~nm}$. (Buckinghamshire, UK). The size and morphology of CdTe QDs were measured by Atomic Force Microscopy (AFM) (NT-MDT, Zelenograd, Russia). UV-vis spectroscopy was performed by a Specord 250 spectrophotometer (Analytik Jena, Germany).

\subsection{Materials and reagents}

Fetal bovine serum (FBS), Dulbecco's modified Eagle medium (DMEM), and penicillin/streptomycin were purchased from Gibco (USA). Oligonucleotides were synthesized and purified by Pishgam Biotech Co (Tehran, Iran), and their sequences were listed in Table S1. $\dagger$ All DNA samples were purified by PAGE and prepared with TE buffer (1 M Tris-HCl, 0.5 M EDTA). $\mathrm{Cd}\left(\mathrm{NO}_{3}\right)_{2}$, tellurium powder, thioglycolic acid (TGA) and sodium borohydride $\left(\mathrm{NaBH}_{4}\right)$ were purchased from Merck and cell culture lysis reagent (CCLR), 5X was purchased from Sigma Aldrich. All other commercially available substances were purchased from Aldrich, Merck and Acros and used without further purification. All other reagents were of analytical reagent grade and ultrapure 
water (Milli-Q plus, Millipore Inc., Bedford, MA) was used in the reactions.

SK-BR-3 cells (human breast cancer cell line) and HEK 293 cells (from normal human embryonic kidney cell line) were used in this study. SK-BR-3 and HEK 293 cells were received from Pasteur Institute, National cell bank of Iran.

\subsection{Preparation of samples for atomic force microscopy (AFM) imaging}

AFM imaging was performed on DNA probes and DNA/miR-155 heteroduplex samples were deposited on freshly cleaved mica sheets. For this, $1 \times 1 \mathrm{~cm}$ mica slides were soaked in $5 \mathrm{mM}$ $\mathrm{MgCl}_{2} .2 \mathrm{~min}$ after, the surface was rinsed with ultra-pure distilled water and dried at room temperature. Then, $50 \mu \mathrm{l}$ of samples in $1 \mathrm{mM} \mathrm{MgCl}$ were spotted onto mica plates and dried at room temperature. After washing the samples with deionized water and drying, AFM imaging was done on a Solver PRO AFM system (NT-MDT, Russia), in a semi-contact (tapping) mode, using Si-gold-coated cantilevers (NT-MDT, Zelenograd, Russia) with a resonance frequency of $375 \mathrm{kHz}$. Images were recorded in height mode, and Nova image processing software (NT-MDT, Zelenograd, Russia) was used for data processing and particle analysis.

\subsection{Preparation of TGA capped-CdTe quantum dots}

The experimental procedure was based on previously reported works. ${ }^{27,37,38}$ In summary, Cd solution $(0.4 \mathrm{mmol})$ and thioglycolic acid (TGA) (1.4 mmol) were solvated in $80 \mathrm{ml}$ distilled water with $\mathrm{pH}$ adjusted to 10.0 using $\mathrm{NaOH}$ solution. Next, sodium borohydrate $(0.8 \mathrm{mmol})$ and Te powder were diluted in $10 \mathrm{ml}$ distilled water in a flask, with vigorous stirring under argon flow. The mixture was heated to $80{ }^{\circ} \mathrm{C}$ to get a clear red NaHTe solution. Cd-TGA solution was heated at $100{ }^{\circ} \mathrm{C}$ under argon flow in a $250 \mathrm{ml}$ three-neck flask. Then the freshly prepared NaHTe solution $(4.0 \mathrm{ml})$ was added to the flask, and the resulting solution was refluxed at $100{ }^{\circ} \mathrm{C}$ for 2 hours.

\subsection{Cell culture}

SK-BR-3 cells (human breast cancer cell line) and HEK 293 cells (from normal human embryonic kidney) were cultured in 25 $\mathrm{cm}^{2}$ tissue culture flasks (SPL, Korea) with $5 \mathrm{ml}$ Dulbecco's modified Eagle's medium (Sigma, UK) containing 10\% heat inactivated fetal bovine serum (Gibco), $100 \mathrm{U} \mathrm{ml}^{-1}$ penicillin (Sigma, UK). Cell lines were grown at $37{ }^{\circ} \mathrm{C}$ in a humidified atmosphere of $5 \% \mathrm{CO}_{2}$ and $95 \%$ air for 5 days until the cell monolayer became confluent. Growth medium was replaced with fresh media every 2 days or as required, indicated by color change due to production of lactic acid and $\mathrm{CO}_{2}$, which leads to low $\mathrm{pH}$. Upon reaching at least $80 \%$ confluence, the cells were washed with phosphate buffered saline (PBS) and trypsinized for $10 \mathrm{~min}$ at $37{ }^{\circ} \mathrm{C}$ with $0.05 \%$ trypsin.

\subsection{Total RNA extraction}

Cell samples was disrupted and total RNA was extracted from SK-BR-3 and HEK 293 cell lines using Cell Culture Lysis Reagent
(CCLR). Approximately $2.0 \times 10^{6}$ cells were collected by lowspeed centrifugation at $1000 \mathrm{rpm}$ for $10 \mathrm{~min}$. Culture medium was carefully removed and the pellet was washed twice with PBS. After carefully removing the PBS, $600 \mu \mathrm{l} \mathrm{CCLR} \mathrm{buffer} \mathrm{was}$ added. Cells were gently resuspended in CCLR buffer with a vortex and incubated for $20 \mathrm{~min}$. Subsequently, $0.2 \mathrm{ml}$ chloroform was added followed by a $20 \mathrm{~s}$ violently vortex. Next, the mixture was centrifuged for $20 \mathrm{~min}$ at $13000 \mathrm{rpm}$ at $4{ }^{\circ} \mathrm{C}$ by refrigerated centrifugation. Adding the same volume of isopropyl alcohol to the upper water which has been taken out and mixing evenly in $-20{ }^{\circ} \mathrm{C}$ precipitation for the night. Afterward, centrifugation for $20 \mathrm{~min}$ at $13000 \mathrm{rpm}$ at $4{ }^{\circ} \mathrm{C}$ was carried out. Next, the supernatant was removed and the rest was washed by $80 \%$ ethanol with DEPC water followed by centrifugation for $20 \mathrm{~min}$ at $13000 \mathrm{rpm}$ at $4{ }^{\circ} \mathrm{C}$. The ethanol was volatilized (letting the tube dry) and the purified RNA was dissolved in an appropriate volume of DEPC water.

\subsection{Assay procedure}

In order to determine the hybridization effects of miRNA targets on fluorescence intensities, different concentrations of miR-155 targets (from 20 to $100 \mathrm{pM}$ ) were added to $10 \mu \mathrm{l}$ of the probe DNA (100 pM) in $40 \mu \mathrm{l}$ of phosphate buffer $(20 \mathrm{mM}, \mathrm{pH}=6.5)$ and heated to $90{ }^{\circ} \mathrm{C}$ for $10 \mathrm{~min}$ (denaturation step). The hybridization was carried out by incubation at $37{ }^{\circ} \mathrm{C}$ for $1 \mathrm{~h}$ (annealing step). After incubation, $10 \mu \mathrm{l}$ of green QDs (100 pM) was added to above solutions. All samples were heated to the set temperature $\left(90^{\circ} \mathrm{C}\right)$ in hot plate. All fluorescence experiments were carried out for all samples before and after heat treating at room temperature.

\subsection{Agarose gel electrophoresis analysis of oligonucleotide- QDs interaction}

Agarose gel (3\% v/v, high melt, medium fragments, Chemos CZ, s.r.o., Prague, Czech Republic) was prepared with $1 \times$ TAE buffer (40 mM Tris, $20 \mathrm{mM}$ acetic acid and $1 \mathrm{mM}$ ethylene diamine tetraacetic acid). $5 \mu$ of samples were prepared with $5 \%(\mathrm{v} / \mathrm{v})$ bromophenol blue and $3 \%(\mathrm{v} / \mathrm{v})$ glycerol and loaded into a gel. The electrophoresis was run at $60 \mathrm{~V}$ and $6{ }^{\circ} \mathrm{C}$ for $20 \mathrm{~min}$ and visualized by UV trans illuminator (312 $\mathrm{nm})$. The mixture samples including ssDNA, dsDNA/miRNA and their corresponding interacted samples (with QDs) were loaded into the gel lanes.

\section{Results and discussion}

3.1 Thermo-responsive based aggregation/disaggregation of CdTe QDs

In this paper, we report a novel single - color fluorescence "offon" switch system by applying melting temperature $\left(T_{\mathrm{m}}\right)$ for sensitive miRNA detection. The system was composed of TGAcapped CdTe QDs (TGA-capped CdTe QDs characterized in Fig $\mathrm{S} 1 \dagger)$ in presence of ssDNA and DNA/miRNA heteroduplex and their different thermo-responsive at $T_{\mathrm{m}}$. Quantitative detection of miRNA could be achieved by measuring the intensity and color change in fluorescence of the reaction solution before and 
after heat treating, respectively. Firstly, the CdTe QDs with maximum emission of $530 \mathrm{~nm}$ (green QDs) and disperse nanoparticles was prepared (Scheme 1a). After heating, the bare QDs solution emitted at $536 \mathrm{~nm}$ (green-yellow fluorescence) due to repulsion force reduction between the QDs (Scheme 1b).

Upon addition of the single-stranded DNA probe to QDs solution, no significant difference was observed in the emission of QDs (Scheme 2a'). It has been suggested that ssDNA (with positive charge of bases) can be rapidly adsorbed onto negatively charged thioglycolic acid capped CdTe QDs surface to act as a coating and stabilizer and therefore by applying melting temperature, the fluorescence emission was completely changed to yellow emission (at $575 \mathrm{~nm}$ ) (Scheme 2b').

But after addition of miR-155 and duplex formation with DNA probe, the interaction between chalcogenide QDs and DNA/miRNA heteroduplex ${ }^{21-27}$ results in aggregation of the QD nanoparticles and their UV-vis absorption coefficient is reduced and therefore, their fluorescence intensity also is reduced ("signal off") ${ }^{28-32}$ (Scheme $3 \mathrm{a}^{\prime}$ ). Then, by applying melting temperature, DNA probe strand dissociated from miRNA and red emission (at $615 \mathrm{~nm}$ ) can be observed ("signal on") 32-36 $\left(\right.$ Scheme $\left.3 b^{\prime}\right)$. This is due to the shorter distances between the CdTe QDs in the dsDNA/miRNA than that of the ssDNA and free CdTe QDs, which can increase the dipole-dipole interaction between the CdTe QDs resulting in a larger Stoke's shift emission change. ${ }^{19}$

\subsection{Atomic force microscopy (AFM) analysis}

In order to confirm the hypothesis of CdTe QDs aggregation in the presence of double-stranded nucleic acid (DNA/miR-155 heteroduplex), and measuring the amount of QDs disaggregation in high temperature, AFM has been carried out on samples (Fig. 1). AFM spectroscopy was expected to confirm these interpretations by direct imaging of surface topographies.
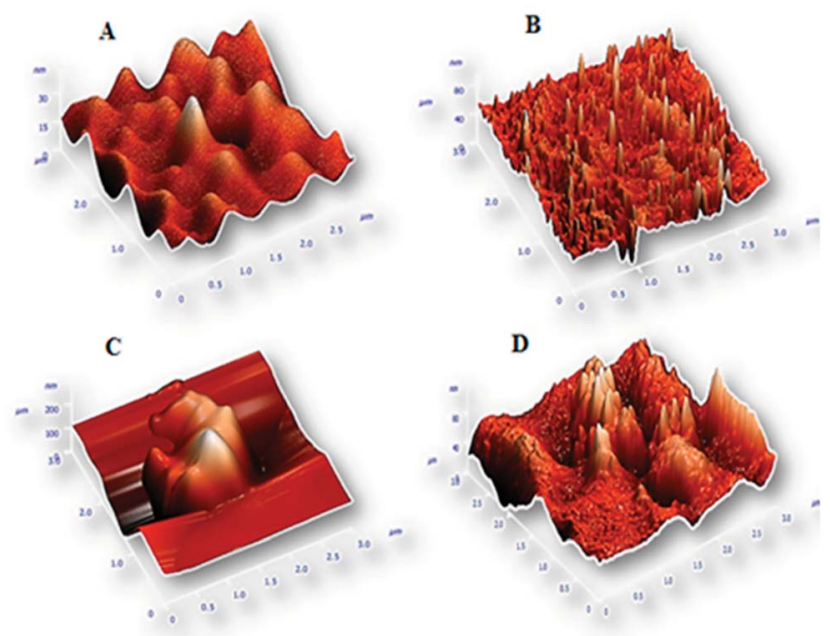

Fig. 1 3D images of CdTe QDs by Atomic Force Microscopy (AFM) scanning of mica surface $(3 \times 3 \mu \mathrm{m})$ prepared by the solution of $(A)$ single strand DNA + QDs before heat treatment, $(B)$ single strand DNA + QDs after heat treatment, (C) double stranded DNA/miR-155 + QDs before heat treatment and (D) double stranded DNA/miR-155 + QDs after heat treatment.
As shown in Fig. 1B, AFM results indicate that by applying $T_{\mathrm{m}}$ the CdTe QDs are dissociated (uncovered) from DNA probe and free DNAs can provide a short inter QDs distance with larger dimensions with a mean diameter of $80 \mathrm{~nm}$ in comparison to DNA-probe@QDs (Fig. 1A) in normal conditions with a mean diameter of $30 \mathrm{~nm}$.

In the presence of miR-155 target and duplex formation with DNA probe, the QDs aggregate and induce a super-molecular structure with a mean diameter of $200 \mathrm{~nm}$ (Fig. 1C). But after applying $T_{\mathrm{m}}$, the double-strands begins to dissociate from each other and following that the QDs de-aggregated relatively reaching a mean diameter of $80 \mathrm{~nm}$ (Fig. 1D). These results are in good agreement with fluorescence emission data in Schemes 2 and 3. And also we took TEM images (Fig. S2 $\dagger$ ) from aggregation/disaggregation phases of double stranded DNA/ miR-155@QDs.

\subsection{Optimization conditions}

In order to obtain the best performance, some effective conditions such as different CdTe QDs concentration, heating time duration and high temperature were optimized.

The efficiency of this assay is greatly dependent on the appropriate molar ratio between the quantum dot and DNA probe. Fig. S3(A) $\dagger$ exhibits the fluorescent emission spectra at different molar ratios of QDs to DNA probe (10, 1 and 0.1, respectively). Molar ratio 1 : 1 was chosen as the optimum ratio, because it led to significant difference in fluorescence intensity between ssDNA and dsDNA/miR-155. In fact, we chose a concentration of the CdTe QDs in which the ratio has the most quenching effect in the presence of dsDNA/miRNA and the smallest quenching in the presence of a single strand DNA probe.

Fig. S3(B) $\dagger$ shows the effect of different temperature $\left(50^{\circ} \mathrm{C}\right.$ to $100^{\circ} \mathrm{C}$ ) with the addition of dsDNA/miR to CdTe QDs. When the temperature was at $90{ }^{\circ} \mathrm{C}$, the color change of fluorescence (red shift) was maximized. It seems that at this temperature the DNA strand is dissociated from RNA strand well.

Finally the effect of heating time duration for dsDNA/miR155 and CdTe QDs over the range of 1-20 min was studied. As shown in the Fig. S3(C), $\dagger$ incubation times which were about 15 min resulted in complete red shift of the QDs fluorescence signal. On the other hand, those more than $15 \mathrm{~min}$ had no significant difference compared to incubation time of $15 \mathrm{~min}$. Therefore, 15 min was regarded as the best choice.

As shown in Fig. 2A, the hybridization with increasing amounts of target miR-155 can specifically decrease the fluorescence intensity of the TGA-CdTe QDs. The decrease fluorescence intensities are linearly proportional to the concentrations of target miR155. After applying $T_{\mathrm{m}}$, with increasing miR-155 concentration the maximum photoluminescence (PL) emission wavelength showed a red-shift from $580 \mathrm{~nm}$ to $615 \mathrm{~nm}$, while the PL emission wavelength also exhibited a red-shift and the fluorescent color under UV irradiation changed from green to green-yellow, yellow and finally red. The red-shift of the maximum PL emission wavelength was due to the increasing of relative aggregation of QDs, while the increasing PL emission intensity was due to the improvement of the crystallization. The decrease of the PL intensity after heat 

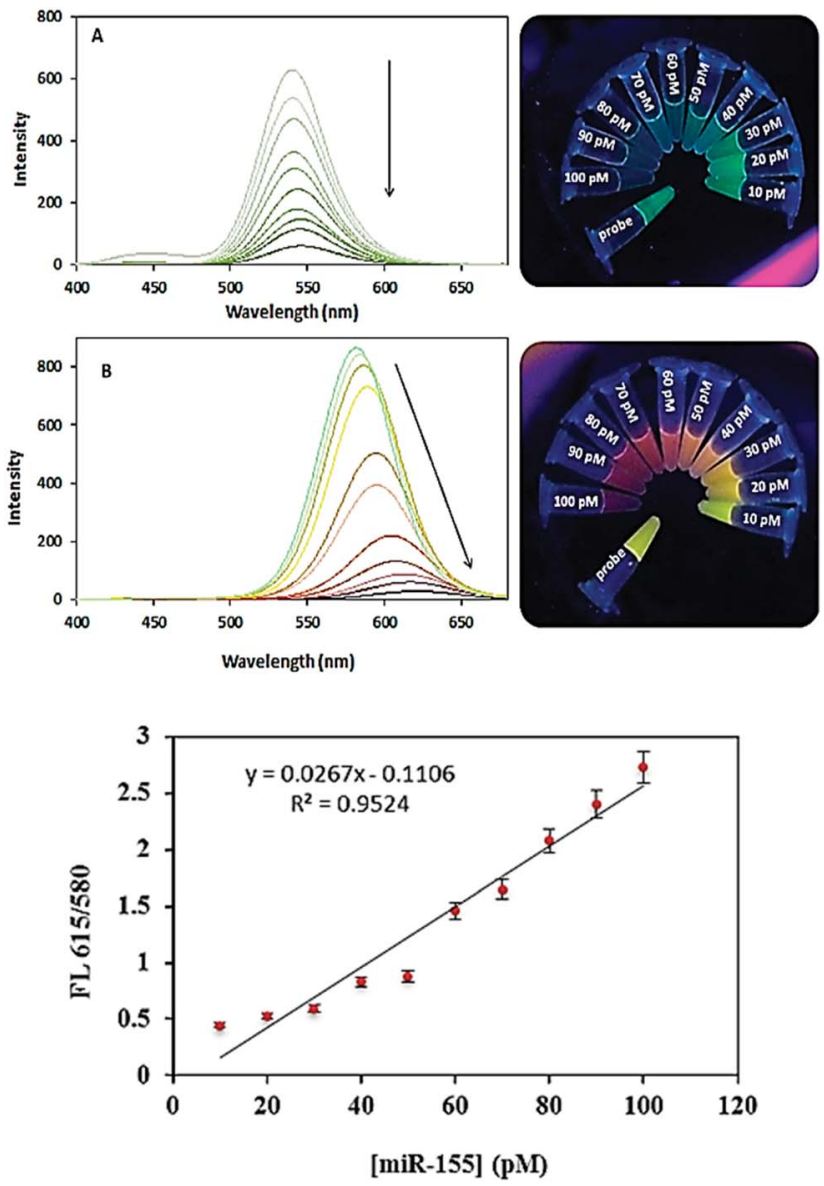

Fig. 2 Emission spectra of dsDNA-QDs complex formed with miR155 target in a concentration ranging 10, 20, 30, 40, 50, 60, 70, 80, 90 and $100 \mathrm{pM}$, before $(\mathrm{A})$ and after $(\mathrm{B})$ heat treatment.

treating resulted from the high concentration, large size and relatively small surface-to-volume ratio of the obtained QDs (Fig. 2B). A linear relationship between the emission intensity of QDs and the miR-155 concentration was obtained the range of 10$100 \mathrm{pM}$. The detection limit is $0.42 \mathrm{pM}(\mathrm{S} / \mathrm{N}=3)$. In addition, compared with other QDs based-sensing methods for miRNA detection ${ }^{39-44}$ the proposed biosensor exhibited acceptable sensitivity while other methods have used labeled probes, enzymes, immobilization (Table 1).

To study aggregation/disaggregation kinetics before and after heating, the S-V plot obtained (Fig. S4 $\dagger$ ) by a Stern-Volmer equation:

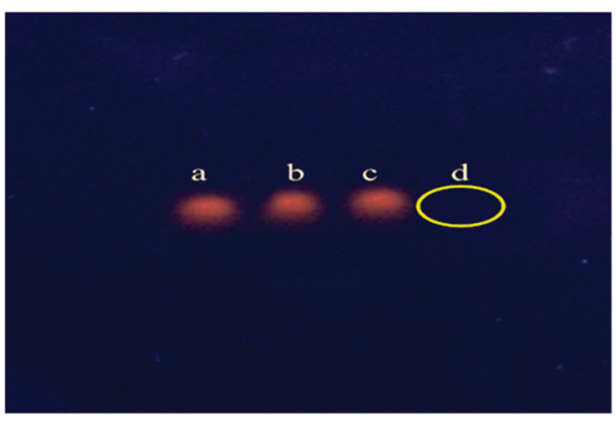

Fig. 3 Gel electrophoresis of (a) the ssDNA probe, (b) the ssDNA complex formed by QDs, (c) the dsDNA formed by miR-155 target, (d) the dsDNA/miR-155 complex formed by QDs.

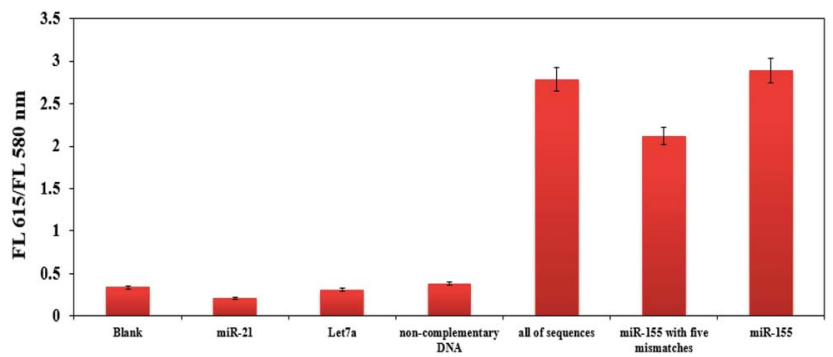

Fig. 4 Plot of FL 615/FL $580 \mathrm{~nm}$ ratio obtained with different miRNA and non-complementary DNA at the same concentration (100 pM).

$$
F_{0} / F=1+K_{\mathrm{SV}}[\mathrm{Q}]
$$

where $F_{0}$ and $F$ are the fluorescence intensity of DNA@QDs in the absence and presence of miRNA-155 respectively, $[\mathrm{Q}]$ is the miRNA-155 concentration, and $K_{\mathrm{SV}}$ is the Stern-Volmer plot, $K_{\mathrm{SV}}$ before and after heating is calculated to be $8.4 \times 10^{12} \mathrm{M}^{-1}$ and $8.8 \times 10^{11} \mathrm{M}^{-1}$, respectively. This was due to the strong binding of QDs to DNA/miR-155 heteroduplex and their aggregation before heating.

\subsection{Gel electrophoresis}

To further confirm the interaction of CdTe QDs with dsDNA/ miRNA, agarose gel electrophoresis was carried out in phosphate buffer. The agarose gel electrophoresis image demonstrated the impact of the binding of CdTe QDs with ssDNA (lane b) and dsDNA/miR-155 (lane d) which is shown in Fig. 3. Different molecular mass or different conformation of DNA will

Table 1 Detection performance comparison of our strategy in miRNA detection with other methods by using quantum dots

\begin{tabular}{llc}
\hline Method & Quantum dot & LOD \\
\hline Electrochemiluminescence resonance energy transfer & CdSe@ZnS QDs & $0.03 \mathrm{fM}$ \\
Catalytic hairpin assembly & CdTe/CdS/ZnS QDs & $37 \mathrm{fM}$ \\
Resonance light scattering & CdTe QDs & $9.4 \mathrm{pM}$ \\
Electrochemiluminescence & Nitrogen doped carbon QDs & $10 \mathrm{aM}$ \\
Fluorescence resonance energy transfer & MoS2 QDs & $0.38 \mathrm{nM}$ \\
Photoelectrochemical aptasensor & CdSe QDs & $4.6 \mathrm{fM}$ \\
Thermo-responsive & CdTe QDs & 42 \\
& & 43 \\
\end{tabular}



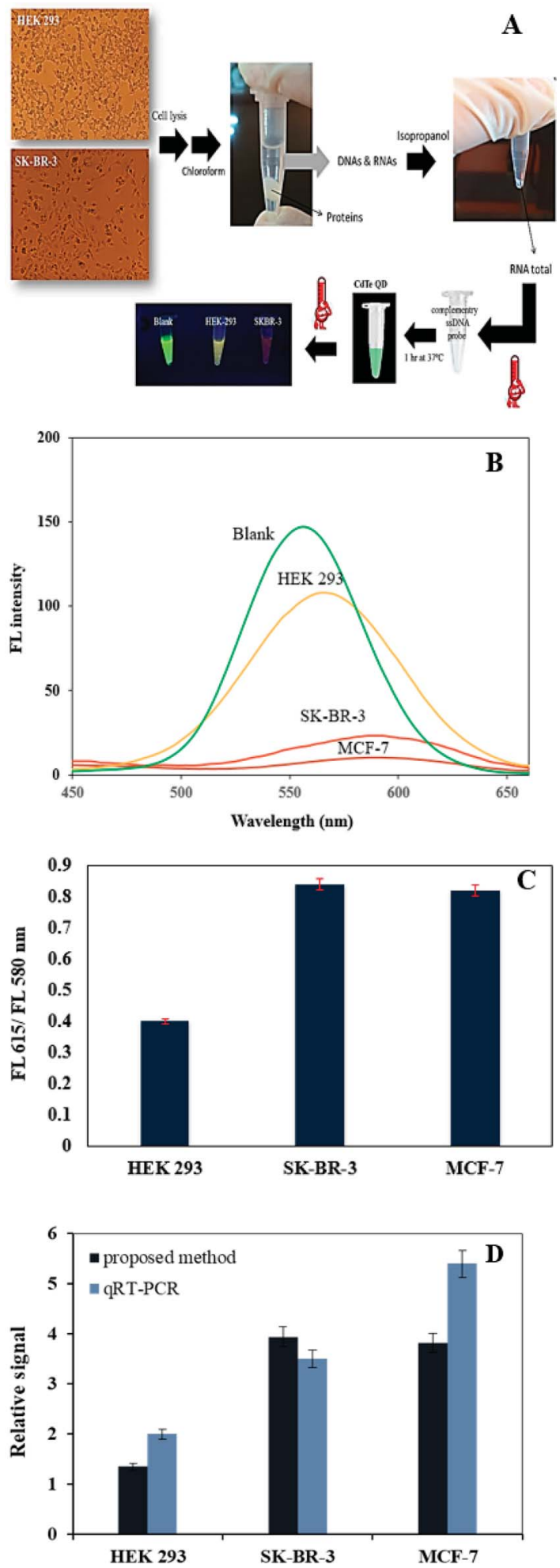

Fig. 5 (A) Workflow of total RNA extraction from HEK 293 (human normal cell line) and MCF-7, SK-BR-3 (breast cancer cell lines). Following extraction, there are three layers: top: aqueous phase: DNAs \& RNAs, middle: debris and proteins, bottom: chloroform. And then transferring of the upper aqueous phase to new microtube, next addition of isopropanol and incubation at $-20^{\circ} \mathrm{C}$ over night and dissolving the purified RNA in an appropriate volume of DEPC water, and (B) emission spectra of DNA@QDs complex formed with total RNA extraction from HEK 293, MCF-7. (C) Plot of FL 615/FL $580 \mathrm{~nm}$ ratio obtained with them (D) comparison of two methods for miR-155 detection: qRT-PCR and the suggested method in this work. appear as different stripes. As shown in Fig. 3, the ssDNA probe was loaded to lane $a$. In the lane $b$ there were mixture samples of lane 1 contents with QDs in ratio $1: 1$. The lane $\mathrm{c}$ was loaded by dsDNA formed by miR-155 target (after hybridization) and finally in the lane $d$ there was mixture sample of lane c contents with QDs in ratio $1: 1$. The low or no brightness of the lane was dependent on the amount of QDs that had interaction with dsDNA/miRNA-QDs (Fig. 3, line d). This is probably due to the fact that DNA-QDs interactions are preventing the DNA to be stained. These results illustrated that gel electrophoresis also could prove the interaction of dsDNA/miRNA and CdTe QDs and help us to distinguish between DNA probe and DNA/miRNA heteroduplex.

\subsection{Specificity}

Selectivity is another important quality index in evaluating performance for the sensing platform described here, as it is a significant challenge for miRNA assays to accurately recognize a specific miRNA in the presence of other miRNAs. DNA probes complementary to miR-155 were designed to distinguish miR155 from non-complementary target DNA, miR-21, Let 7a and mixture of all sequences at the same concentration of $100 \mathrm{pM}$. As the results are shown in Fig. 4, the fluorescence shift of the DNA probe toward the perfectly matched target miR-155 was much larger than that other sequences which were closed to that of the blank sample. Also, this method is specifically capable of detecting miR-155 in the presence of other miRNAs and DNA sequence. These results confirm the high specificity for miRNA detection in this method.

\subsection{Detection of cellular microRNA-155}

To investigate the feasibility of this proposed assay to biological samples, we applied this method to detect miR-155 in total RNA extraction from human breast carcinoma SK-BR-3, MCF-7 cells and normal HEK 293 cells. The fluorescence response of the CdTe QDs based system in total RNA extracts was recorded (Fig. 5). RNA extracts obtained from SK-BR-3 (73.8 $\mathrm{ng}^{\mu \mathrm{l}^{-1}}$ ), MCF-7 (103.2 $\mathrm{ng} \mu \mathrm{l}^{-1}$ ) and HEK 293 (63.4 $\mathrm{ng} \mu \mathrm{l}^{-1}$ ) were mixed with hybridization ssDNA probe and the QDs and then we initialized the temperature treatment. As shown in Fig. 5, the wavelength emission of the system for the SK-BR-3 and MCF-7 was around $595 \mathrm{~nm}$ and for HEK 293 was around $565 \mathrm{~nm}$. The same samples were also tested by quantitative real-time PCR (qRT-PCR) method. The results show that miR-155 had different expression levels in HEK 293 (human normal cell) and MCF-7, SK-BR-3 (human breast cancer cells). The cell lysate from SK-BR-3 and MCF-7 had a higher concentration of miR155 than that of HEK 293. The results obtained by the suggested strategy in this work were in good agreement with RTPCR and also consistent with previously published data by standard methods. ${ }^{45,46}$

\section{Conclusion}

In summary, we developed a facile switchable fluorescent CdTe QD probe for microRNA-155 detection. The switching 
mechanism is based on QDs aggregation in the presence of double stranded DNA/miR-155 (due to interaction between dsDNA/miR-155 and QDs) and applying melting temperature triggered QDs disaggregation (due to dissociation of miR strand from DNA probe). Taking advantage of the flexible processability of QDs, this switchable fluorescent probe has great promise for the detection of various targets, such as other microRNAs and gene detection.

\section{Conflicts of interest}

There are no conflicts to declare.

\section{Acknowledgements}

The authors are grateful to the Iran National Science Foundation (INSF 96010584) and the Tehran University (Grant 28645/ 01/02) for the financial support of this work.

\section{References}

1 G. Higgs and F. Slack, J. Clin. Bioinf., 2013, 3, 17.

2 G. Bertoli, C. Cava and I. Castiglioni, Theranostics, 2015, 5, 1122.

3 S. C. Eastlack and S. K. Alahari, Non-Coding RNA, 2015, 1, 7. 4 Z. Chen, T. Ma, C. Huang, T. Hu and J. Li, J. Cell. Physiol., 2014, 229, 545.

5 K. Zhang, Y. Zhang, C. Liu, Y. Xiong and J. Zhang, Int. J. Oncol., 2014, 45, 950.

6 S. Persano, M. L. Guevara, J. Wolfram, E. Blanco, H. Shen, M. Ferrari and P. P. Pompa, ACS Omega, 2016, 1, 448.

7 T. Tian, J. Wang and X. Zhou, Org. Biomol. Chem., 2015, 13, 2226.

8 E. A. Hunt, D. Broyles, T. Head and S. K. Deo, Annu. Rev. Anal. Chem., 2015, 8, 217.

9 Y. S. Borghei, M. Hosseini, M. Khoobi and M. R. Ganjali, J. Fluoresc., 2017, 27, 529.

10 Y. S. Borghei, M. Hosseini, M. R. Ganjali and S. Hosseinkhani, J. Pharm. Biomed. Anal., 2018, 15, 81.

11 Y. S. Borghei, M. Hosseini and M. R. Ganjali, Microchim. Acta, 2017, 184, 4713.

12 Y. S. Borghei, M. Hosseini, M. R. Ganjali and S. Hosseinkhani, Sens. Actuators, B, 2017, 248, 133.

13 M. Hosseini, A. Akbari, M. R. Ganjali, M. Dadmehr and A. H. Rezayan, J. Fluoresc., 2015, 25, 925.

14 M. Hosseini, S. Mohammadi, Y. S. Borghei and M. R. Ganjali, J. Fluoresc., 2017, 27, 1443.

15 M. Dadmehr, M. Hosseini, S. Hosseinkhani, M. R. Ganjali and R. Sheikhnejad, Biosens. Bioelectron., 2015, 73, 108.

16 R. Zhang, D. Zhao, H. G. Ding, Y. X. Huang, H. Z. Zhong and H. Y. Xie, Biosens. Bioelectron., 2014, 56, 51.

17 Y. Yuan, J. Zhang, G. Liang and X. Yang, Analyst, 2012, 137, 1775.

18 K. D. Wegner and N. Hildebrandt, Chem. Soc. Rev., 2015, 44, 4792 .

19 S. K. Kailasa, K. H. Cheng and H. F. Wu, Materials, 2013, 6, 5763.
20 W. R. Algar and U. J. Krull, J. Colloid Interface Sci., 2011, 359, 148.

21 Z. Wang, H. He, W. Slough, R. Pandey and S. P. Karna, J. Phys. Chem. C, 2015, 119, 25965.

22 W. R. Algar and U. J. Krull, Langmuir, 2006, 22, 11346.

23 S. S. Narayanan, S. S. Sinha, P. K. Verma and S. K. Pal, Chem. Phys. Lett., 2008, 463, 160.

24 Q. Xu, J. H. Wang, Z. Wang, Z. H. Yin, Q. Yang and Y. D. Zhao, Electrochem. Commun., 2008, 10, 1337.

25 S. Anandampillai, X. Zhang, P. Sharma, G. C. Lynch, M. A. Franchek and K. V. Larin, Comput. Methods Appl. Mech. Eng., 2008, 197, 3378.

26 L. Y. Zhang, H. Z. Zheng, Y. J. Long, C. Z. Huang, J. Y. Hao and D. B. Zhou, Talanta, 2011, 83, 1716.

27 Y. S. Borghei, M. Hosseini and M. R. Ganjali, Microchim. Acta, 2017, 1.

28 V. Poderys, M. Matulionyte, A. Selskis and R. Rotomskis, Nanoscale Res. Lett., 2010, 6, 9.

29 A. A. Ensafi, N. Kazemifard and B. Rezaei, Biosens. Bioelectron., 2016, 77, 499.

30 M. Hosseini, M. R. Ganjali, A. Jarrahi, Z. vaezi, F. Mizani and F. Faridbod, Spectrochim. Acta, Part A, 2014, 132, 629.

31 M. Noh, T. Kim, H. Lee, C. K. Kim, S. W. Joo and K. Lee, Colloids Surf., A, 2010, 359, 39.

32 J. Liu, X. Yang, K. Wang, R. Yang, H. Ji, L. Yang and C. Wu, Chem. Commun., 2011, 47, 935.

33 S. D. Quinn and S. W. Magennis, RSC Adv., 2017, 7, 24730.

34 M. Gilic, N. Romcevic, M. Romcevic, D. Stojanovic, R. Kostic, J. Trajic, W. D. Dobrowolski, G. Karczewski and R. Galazka, J. Alloys Compd., 2013, 579, 330.

35 A. Polimeni, A. Patane, M. Henini, L. Eaves and P. C. Main, Phys. Rev. B, 1999, 59, 5064.

36 A. J. Chiquito, Y. A. Pusep, S. Mergulhão, Y. G. Gobato, J. C. Galzerani and N. Moshegov, Mater. Res., 2004, 7, 459.

37 M. Hosseini, M. R. Ganjali, Z. Vaezi, B. Arabsorkhi, M. Dadmehr, F. Faridbod and P. Norouzi, Sens. Actuators, $B, 2015,210,349$.

38 F. S. Sabet, M. Hosseini, H. Khabbaz, M. Dadmehr and M. R. Ganjali, Food Chem., 2017, 220, 527.

39 P. Zhang, Z. Li, H. Wang, Y. Zhuo, R. Yuan and Y. Chai, Nanoscale, 2017, 9, 2310.

40 R. Yuan, X. Yu, Y. Zhang, L. Xu, W. Cheng, Z. Tu and S. Ding, Biosens. Bioelectron., 2017, 92, 342.

41 S. Lv, F. Chen, C. Chen, X. Chen, H. Gong and C. Cai, Talanta, 2017, 165, 659.

42 Q. Liu, C. Ma, X. P. Liu, Y. P. Wei, C. J. Mao and J. J. Zhu, Biosens. Bioelectron., 2017, 92, 273.

$43 \mathrm{X}$. Yu, L. Hu, F. Zhang, M. Wang, Z. Xia and W. Wei, Microchim. Acta, 2018, 185, 239.

44 X. Cong, M. Zhou, T. Hou, Z. Xu, Y. Yin, X. Wang and M. Yin, Electroanalysis, 2018, 30, 1140.

45 R. Dinami, C. Ercolani, E. Petti, S. Piazza, Y. Ciani, R. Sestito, A. Sacconi, F. Biagioni, C. Le Sage, R. Agami and R. Benetti, Cancer Res., 2014, 74, 4145.

46 M. C. Casey, K. J. Sweeney, J. A. Brown and M. Kerin, Int. J. Cancer, 2016, 139, 12. 